\title{
Hepatoprotective effect of crude polysaccharides extracted from Ganoderma lucidum against carbon tetrachloride-induced liver injury in mice
}

\author{
Raden Joko Kuncoroningrat Susilo시 , Dwi Winarni ${ }^{1}$, Saikhu Akhmad Husen ${ }^{1}$, Suhailah Hayaza ${ }^{1}$, Hunsa Punnapayak ${ }^{1,2}$ \\ Sri Puji Astuti Wahyuningsih ${ }^{1}$, Elma Sakinatus Sajidah ${ }^{1}$ and Win Darmanto ${ }^{1}$ \\ 1. Department of Biology, Faculty of Science and Technology, Universitas Airlangga, Surabaya 60115, Indonesia; 2. Plant \\ Biomass Utilization Research Unit, Department of Botany, Faculty of Science, Chulalongkorn University, Bangkok 10330, \\ Thailand. \\ Corresponding author: Win Darmanto, e-mail: windarmanto@fst.unair.ac.id \\ Co-authors: RJKS: raden.joko.kuncoroningrat-2017@fst.unair.ac.id, DW: dwiwinarni44@gmail. com, \\ SAH: saikhu-a-h@fst.unair.ac.id, SH: suhailah-2017@fst.unair.ac.id, HP: hunsa.p@chula.ac.th, \\ SPAW: sri-p-a-w@fst.unair.ac.id, ESS: elma.sakinatus-13@fst.unair.ac.id \\ Received: 01-08-2019, Accepted: 08-11-2019, Published online: 17-12-2019
}

doi: www.doi.org/10.14202/vetworld.2019.1987-1991 How to cite this article: Susilo RJK, Winarni D, Husen SA, Hayaza S, Punnapayak H, Wahyuningsih SPA, Sajidah ES, Darmanto W (2019) Hepatoprotective effect of crude polysaccharides extracted from Ganoderma lucidum against carbon tetrachloride-induced liver injury in mice, Veterinary World, 12(12):1987-1991.

\begin{abstract}
Background and Aim: Natural products are currently widely used as alternative treatments for liver disease. The study aimed to determine the hepatoprotective effect of crude polysaccharides extracted from Ganoderma lucidum against liver injury induced by carbon tetrachloride $\left(\mathrm{CCl}_{4}\right)$.

Materials and Methods: Twenty-four male BALB/C mice were randomly divided into six groups. Serum and liver samples were taken on day 10 after $G$. lucidum administration. The levels of alanine aminotransferase (ALT), aspartate aminotransferase (AST), malondialdehyde (MDA), superoxide dismutase (SOD), and catalase (CAT) were measured using enzyme-linked immunosorbent assays, and the histology of the liver was evaluated using light microscopy.

Results: G. lucidum extract significantly decreased the levels of ALT, AST, and MDA and significantly increased the levels of SOD and CAT. In the histological evaluation, the liver tissue of $\mathrm{CCl}_{4}$-treated mice exhibited hydropic degeneration, necrosis, and sinusoidal dilatation. G. lucidum extract administration improved this liver tissue histopathology.
\end{abstract}

Conclusion: Crude polysaccharides extracted from G. lucidum showed a hepatoprotective effect, regenerating damaged liver tissue.

Keywords: carbon tetrachloride, crude polysaccharide extract, Ganoderma lucidum, hepatotoxicity.

\section{Introduction}

The liver is an important homeostatic organ and is involved in the process of detoxifying harmful drugs and chemicals. Given that, the incidence of jaundice and hepatitis has increased the development of hepatoprotective drugs from natural sources which is necessary. Liver damage may arise from excessive alcohol intake or exposure to toxins and environmental pollutants and can progress into severe liver diseases such as hepatitis, cirrhosis, and liver cancer $[1,2]$. Reactive oxygen species (ROS) cause cellular damage in the liver [3], and increased ROS can be caused by exposure to toxic substances such as carbon tetrachloride $\left(\mathrm{CCl}_{4}\right)$ [4]. Therefore, $\mathrm{CCl}_{4}$ is often used to induce liver damage in model animals. $\mathrm{CCl}_{4}$-induced hepatotoxicity occurs through a metabolic process by cytochrome

Copyright: Susilo, et al. Open Access. This article is distributed under the terms of the Creative Commons Attribution 4.0 International License (http://creativecommons.org/licenses/by/4.0/), which permits unrestricted use, distribution, and reproduction in any medium, provided you give appropriate credit to the original author(s) and the source, provide a link to the Creative Commons license, and indicate if changes were made. The Creative Commons Public Domain Dedication waiver (http://creativecommons.org/ publicdomain/zero/1.0/) applies to the data made available in this article, unless otherwise stated.
P450 which produces trichloromethyl radicals. These react with sulfhydryl groups, for example, reduced glutathione and thiol proteins, disrupting the physiological function of liver cells and ultimately inducing cell necrosis [5]. These radicals increase lipid metabolism, resulting in a decrease in the transport of these lipids and causing steatosis or fatty liver. The breakdown of these radicals forms reactive aldehyde, which increases membrane permeability and ultimately causes cell death. The dominance of pro-oxidants over antioxidants causes oxidative stress which can damage proteins, carbohydrates, nucleotides, and lipids [6]. Liver sections of $\mathrm{CCl}_{4}$-treated mice show hepatocyte necrosis, hemorrhage, vacuolar change, and hydropic degeneration [7]. In addition, liver sections of $\mathrm{CCl}_{4}$-treated rabbits show a total loss of hepatic architecture with fatty changes, sinusoidal congestion, and intense necrosis [8].

Antioxidants could potentially be used for the prevention and treatment of many diseases associated with ROS. Polysaccharides extracted from fungi, plants, bacteria, and algae are potential sources of antioxidants [9]. Natural products are currently widely used as alternative treatments for liver disease [10]. Polysaccharides are the active compounds of the 
Ganoderma lucidum fungus and can be extracted from the fruiting body and mycelium. The previous research has shown that polysaccharides have immunomodulatory, anticancer, and anti-aging effects and can lower blood sugar levels [11-13]. G. lucidum can also reduce liver damage caused by chemicals and oxidative stress [14]. However, the hepatoprotective effect of polysaccharides extracted from G. lucidum against liver damage in animal models remains unclear. Silymarin is a polyphenolic flavonoid isolated from milk thistle (Silybum marianum) which has a history as a medical plant for almost two millennia. Some studies indicate that silymarin shows strong antioxidant activity, and it is used clinically in Europe and Asia for the treatment of liver disease $[15,16]$. In this study, silymarin was used as a positive control.

This study aimed to explore the hepatoprotective effect of crude polysaccharides extracted from G. lucidum against liver damage in $\mathrm{CCl}_{4}$-treated mice.

\section{Materials and Methods}

\section{Ethical approval}

Ethical approval for this study was obtained from the Committee of Animal Care and Use, Faculty of Veterinary Medicine, Universitas Airlangga, Surabaya, Indonesia (approval no. 2.KE.168.10.2018).

\section{Materials and chemicals}

G. lucidum basidiocarps were obtained from Tulungagung, East Java, Indonesia. Taxonomic identification of $G$. lucidum was carried out by Dr. Ni'matuzahroh from the Department of Biology, Faculty of Science and Technology, Airlangga University, Surabaya, Indonesia. Alanine aminotransferase (ALT), aspartate aminotransferase (AST), malondialdehyde (MDA), superoxide dismutase (SOD), and catalase (CAT) enzyme-linked immunosorbent assay (ELISA) kits were purchased from Bioassay Technology Laboratory (Shanghai, China). All other chemicals and solvents used were of analytical grade.

\section{Preparation of crude polysaccharides from G. Iucidum}

Dried G. lucidum powder was extracted with water at $90-100^{\circ} \mathrm{C}$ for $6 \mathrm{~h}$. The solution was centrifuged at $4300 \times g$ for $5 \mathrm{~min}$. The whole extract was filtered, concentrated, and centrifuged, and the supernatant was precipitated with absolute ethanol $(3 \times$ volume of supernatant) at $4^{\circ} \mathrm{C}$ overnight. The resulting precipitate was washed with $70 \%$ ethanol and dried under vacuum at $40^{\circ} \mathrm{C}$ to obtain the crude polysaccharides.

\section{Animals}

Male BALB/C mice with a bodyweight (bw) of $25 \pm 2 \mathrm{~g}$ were obtained from the Faculty of Pharmacy, Universitas Airlangga (Surabaya, Indonesia). They were maintained under a controlled temperature of $25 \pm 2^{\circ} \mathrm{C}$, humidity of $50 \pm 10 \%$, and a $12 \mathrm{~h}$ light-dark cycle and had free access to food and water.

\section{Experimental design}

Mice were randomly divided into six groups $(n=4 /$ each). Group I (the normal control) was orally administered $0.5 \%$ carboxymethyl cellulose (CMC) once a day for 8 days and was administered an intraperitoneal injection of olive oil on day 9; Group II (the silymarin group) was orally administered $50 \mathrm{mg} / \mathrm{kg}$ bw silymarin daily for 8 days and was administered an intraperitoneal injection of $\mathrm{CCl}_{4}$ on day 9; Group III (the $\mathrm{CCl}_{4}$ group) was orally administered $0.5 \% \mathrm{CMC}$ daily for 8 days and was administered an intraperitoneal injection of $\mathrm{CCl}_{4}$ on day 9; Group IV (the low G. lucidum group) was orally administered $50 \mathrm{mg} / \mathrm{kg}$ bw G. lucidum daily for 8 days and was administered an intraperitoneal injection of $\mathrm{CCl}_{4}$ on day 9; Group V (the medium G. lucidum group) was orally administered $100 \mathrm{mg} / \mathrm{kg}$ bw G. lucidum daily for 8 days and was administered an intraperitoneal injection of $\mathrm{CCl}_{4}$ on day 9; and Group VI (the high G. lucidum group) was orally administered $200 \mathrm{mg} / \mathrm{kg}$ bw G. lucidum daily for 8 days and was administered an intraperitoneal injection of $\mathrm{CCl}_{4}$ on day 9. The G. lucidum extract and silymarin suspension were suspended in $0.5 \% \mathrm{CMC}$. $\mathrm{CCl}_{4}$ was dissolved in olive oil $(1 \% \mathrm{~V} / \mathrm{V}$, $5 \mathrm{~mL} / \mathrm{kg}$ ). On day 10 , mice were anesthetized with ketamine/xylazine and sacrificed by cervical dislocation. Serum samples were collected in tubes. Liver samples were quickly excised and washed immediately in phosphate-buffered saline (PBS) to remove blood. One part of each liver sample was immediately stored at $-20^{\circ} \mathrm{C}$ until analysis, and the other was fixed in 10\% formalin solution for histopathologic analysis.

\section{Measurement of serum AST and ALT levels}

Blood samples were collected in tubes and then centrifuged at $3000 \times g$ for $20 \mathrm{~min}$. To assess liver damage, serum AST and ALT levels were assayed using ELISA kits.

\section{Measurement of hepatic MDA, SOD, and CAT levels}

Liver samples were homogenized in PBS $(3 \mathrm{~mL})$ to produce liver homogenates. The homogenates were then centrifuged at $3000 \times \mathrm{g}$ for $20 \mathrm{~min}$ at $4^{\circ} \mathrm{C}$. The levels of MDA, SOD, and CAT in the supernatants were then measured using ELISA kits, according to the manufacturer's instructions.

\section{Histological examination}

The fresh liver tissues were trimmed into 3-mm thick slices, placed in cassettes, and immersed in neutral buffered formalin for $24 \mathrm{~h}$. The fixed tissues were embedded in paraffin, sectioned, deparaffinized, and rehydrated using standard techniques. To examine histological changes, the liver sections were stained with hematoxylin and eosin and were subsequently examined under a light microscope (OLYMPUS CX23) at $40 \times$.

\section{Statistical analysis}

Data are expressed as mean \pm standard deviation. Differences between the groups were analyzed using one-way analysis of variance followed by Duncan's post hoc test using SPSS version 21 (SPSS Inc., Chicago, IL, USA). $\mathrm{p}<0.05$ was considered statistically significant. 


\section{Results}

Effect of G. Iucidum on serum ALT and AST levels

The $\mathrm{CCl}_{4}$-treated mice exhibited significantly increased levels of ALT and AST compared to the control group. However, G. lucidum treatment for 8 days significantly decreased the levels of ALT and AST (Table-1).

\section{Effect of G. lucidum on hepatic MDA, SOD, and CAT levels}

The $\mathrm{CCl}_{4}$-treated mice exhibited significantly increased hepatic MDA levels and significantly decreased SOD and CAT levels compared to the normal control group. The administration of G. lucidum extract attenuated these $\mathrm{CCl}_{4}$-induced alterations in MDA, SOD, and CAT levels (Table-2).

\section{Effect of G. lucidum on histological changes in the liver}

The liver tissue of the normal control group exhibited normal liver architecture such as distinct hepatocytes, sinusoidal spaces, and a clear central vein. The liver tissue of the $\mathrm{CCl}_{4}$-administered silymarin group showed only mild hydropic degeneration and a low number of necrotic cells. The liver tissue of the $\mathrm{CCl}_{4}$-treated group showed a high number of necrotic cells, hydropic degeneration, and sinusoidal dilatation. The liver tissue of the group administered a $50 \mathrm{mg} / \mathrm{kg}$ bw dose of $\mathrm{G}$. lucidum extract showed sinusoidal dilatation and moderate hydropic degeneration and necrosis. The liver tissue of the group administered a $100 \mathrm{mg} / \mathrm{kg}$ bw dose of G. lucidum extract showed reduced hydropic degeneration and fewer necrotic and inflammatory cells. The liver tissue of the group administered a $200 \mathrm{mg} / \mathrm{kg}$ bw dose of

Table-1: Effect of G. lucidum extract on liver marker enzymes in mice treated with carbon tetrachloride.

\begin{tabular}{lcc}
\hline Group & ALT & AST \\
\hline Normal control & $8.351 \pm 2.35$ & $12.301 \pm 4.3$ \\
Silymarin & $6.718 \pm 1.356$ & $16.234 \pm 0.734$ \\
Carbon tetrachloride & $16.180 \pm 4.158^{* * *}$ & $29.644 \pm 4.009 * * *$ \\
Low G. lucidum & $5.777 \pm 0.339 * *$ & $11.279 \pm 0.195$ \\
Medium G. lucidum & $5.637 \pm 0.517 * *$ & $11.224 \pm 0.503$ \\
High G. lucidum & $5.711 \pm 0.665$ & $10.680 \pm 1.1$ \\
\hline
\end{tabular}

Data are expressed as mean \pm standard deviation $(n=6)$.

$* * p<0.05$ compared to the normal control group.

$* * * \mathrm{p}<0.05$ compared to all groups. ALT=Alanine

transaminase, AST=Aspartate transaminase,

G. Iucidum=Ganoderma lucidum
G. lucidum extract showed very little hydropic degeneration and necrosis (Figure-1).

\section{Discussion}

Recently, natural products have become widely used for the treatment of liver disease. This study aimed to investigate the hepatoprotective effect of crude polysaccharides extracted from G. lucidum against liver damage in mice. Polysaccharides, found in animals, plants, and other microorganisms, have antioxidant and anti-inflammatory potential and can protect the liver from damage caused by exposure to chemicals $[17,18]$. G. lucidum has been reported to have antitumor, cardioprotective, antioxidant, antibacterial, and antiviral effects [19-21]. In the previous studies, G. lucidum extract prevented damage caused by diseases associated with ROS [22-24]. Furthermore, the protective effect of $G$. lucidum extract against oxidative stress-induced liver damage has been investigated. In this study, the protective effect of polysaccharides extracted from G. lucidum against $\mathrm{CCl}_{4}$-induced hepatotoxicity was investigated.

$\mathrm{CCl}_{4}$-induced liver damage is commonly used to experimentally study the hepatoprotective effects of drugs [25,26]. Cytochrome P450 metabolizes $\mathrm{CCl}_{4}$ to trichloromethyl radicals $\left(\mathrm{CCl}_{3}^{-}\right)$in the endoplasmic reticulum of liver cells, and these bind to $\mathrm{O}_{2}$ to form trichloromethyl peroxyl $\left(\mathrm{CCl}_{3} \mathrm{OO}^{-}\right)$radicals. These radicals subsequently bind to cell molecules such as unsaturated fatty acids, ultimately causing lipid peroxidation. Furthermore, the structure and function of the cell membrane become disrupted. In this study, $\mathrm{CCl}_{4}$ administration induced acute damage to liver cells, demonstrated by increased serum ALT and AST levels. ALT and AST are often considered sensitive markers for diagnosing liver damage due to their presence of the cytoplasm facilitates blood flow after liver cell damage [27]. In this study, G. lucidum extract significantly reduced ALT and AST levels, demonstrating that it can prevent cell damage.

The histological results obtained correlated with the aforementioned biochemical results. Histological signs of liver damage include hydropic degeneration, inflammation, and necrosis. The increasing permeability of the liver cell membrane causes metabolic disorders, inhibits protein synthesis, and produces necrosis-inducing cellular degradative enzymes. The increased number of inflammatory cells in damaged

Table-2: Effect of G. Iucidum extract on MDA, SOD, and CAT levels in mice treated with carbon tetrachloride.

\begin{tabular}{lccc}
\hline Group & MDA & SOD & CAT \\
\hline Normal control & $1.246 \pm 0.126$ & $5.945 \pm 1.145$ & $2.852 \pm 0.716$ \\
Silymarin & $1.543 \pm 0.152^{* *}$ & $6.057 \pm 1.082$ & $3.119 \pm 0.366$ \\
Carbon tetrachloride & $2.858 \pm 0.303^{* * *}$ & $4.621 \pm 0.207 * * *$ & $2.312 \pm 0.080^{* * *}$ \\
Low G. lucidum & $1.952 \pm 0.329 * *$ & $5.671 \pm 0.525$ & $2.797 \pm 0.360$ \\
Medium G. Iucidum & $1.892 \pm 0.146 * *$ & $6.236 \pm 0.869$ & $3.009 \pm 0.466$ \\
High G. lucidum & $1.510 \pm 0.219$ & $6.246 \pm 0.814$ & $3.178 \pm 0.368$ \\
\hline
\end{tabular}

Data are expressed as mean \pm standard deviation $(\mathrm{n}=6) . * * \mathrm{p}<0.05$ compared to the normal control group. $* * * \mathrm{p}<0.05$ compared to all groups. MDA=Malondialdehyde, $\mathrm{SOD}=$ Superoxide dismutase, $\mathrm{CAT}=$ Catalase, G. lucidum=Ganoderma lucidum 


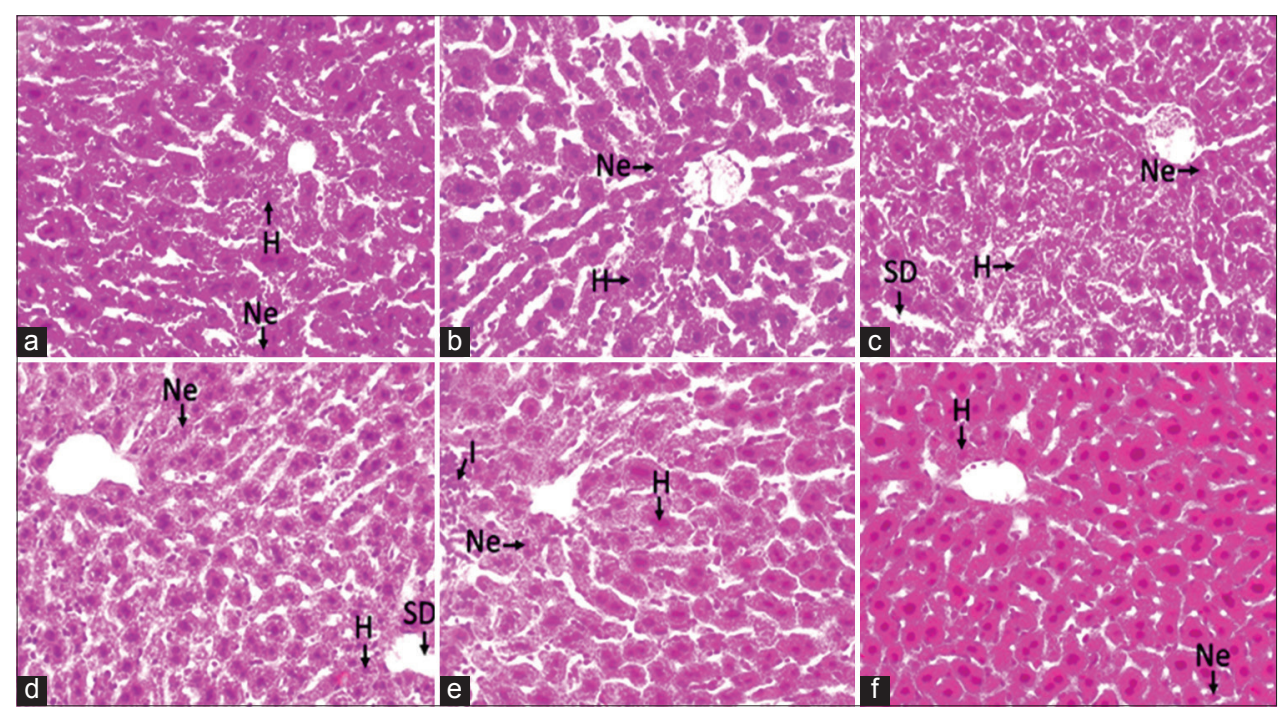

Figure-1: Effect of Ganoderma lucidum extract on liver histology in mice. N=Normal cell, $\mathrm{Ne}=\mathrm{Necrotic}$ cell, $\mathrm{H}=\mathrm{Hydropic}$ cell, SD=Sinusoidal dilatation, I=Inflammation. (a) Normal control group; (b) silymarin group; (c) carbon tetrachloride group; (d) low G. Iucidum (50 mg/kg body weight [bw]) group; (e) medium G. lucidum (100 mg/kg bw) group; (f) high G. Iucidum $(200 \mathrm{mg} / \mathrm{kg}$ bw) group.

liver cells causes an increase in ROS levels. Hydropic cells are formed when the membrane cell transport system fails, resulting in excessive water in the cell. The liver tissue of the mice administered G. lucidum showed histopathological improvements, indicating that $\mathrm{G}$. lucidum can protect against $\mathrm{CCl}_{4}$-induced liver damage.

Lipid peroxidation in the liver cell membrane is an important oxidative stress parameter. In addition, lipid peroxidation is also caused by free radicals derived from $\mathrm{CCl}_{4}$ [28]. The increased levels of MDA noted after $\mathrm{CCl}_{4}$ administration indicate the occurrence of lipid peroxidation. This demonstrates the occurrence of liver cell damage and the failure of antioxidants to prevent abundant free radicals [29]. In this study, the administration of G. lucidum significantly reduced MDA levels. This extract can act as a free radical scavenger and can protect membrane lipids from oxidative damage. Cell protection against free radical attacks is dependent on radical scavengers such as SOD and CAT. SOD converts superoxide radicals to $\mathrm{H}_{2} \mathrm{O}_{2}$, and this is then metabolized by CAT into $\mathrm{H}_{2} \mathrm{O}$ and $\mathrm{O}_{2}$, ultimately preventing liver cell damage caused by these free radicals [30]. SOD and CAT levels increased in the mice administered G. lucidum, demonstrating that $G$. lucidum extract can restore and maintain the activity of SOD and CAT. The previous studies have suggested that $\mathrm{CCl}_{4}$ reduces the activity of antioxidant enzymes and causes hepatopathy $[31,32]$. The administration of G. lucidum can thus protect against free radicals, protecting hepatocytes from hepatopathy.

\section{Conclusion}

In this study, G. lucidum administration decreased the levels of ALT, AST, and MDA and increased the levels of SOD and CAT in $\mathrm{CCl}_{4}$-treated mice. This indicates that G. lucidum has significant hepatoprotective activity, which likely results from its antioxidant activity. Ultimately, G. lucidum could be developed as a novel protective agent against acute liver damage.

\section{Authors' Contributions}

WD has made a significant contribution to conception, design, interpretation of data, drafting, revising the manuscript, and gave final approval of the version to be published. RJKS made a substantial contribution to the acquisition of data, analysis, and drafting of the manuscript. DW designed the study, analyzed data, drafted the article, and made critical revision. SAH helped in collection data, edited article, and made critical revisions. SH analyzed data and draft articled. HP performed drafted the article and made critical revision. SPAW edited the article and made critical revisions. ESS participated in collection data. All authors read and approved the final manuscript.

\section{Acknowledgments}

This study was supported by the grant from mandate research of Universitas Airlangga, Indonesia (886/UN3/2018). The authors would like to thank Editage (www.editage.com) for English language editing.

\section{Competing Interests} interests.

The authors declare that they have no competing

\section{Publisher's Note}

Veterinary World remains neutral with regard to jurisdictional claims in published institutional affiliation.

\section{References}

1. Ghabril, M., Chalasani, N. and Björnsson, E. (2010) Drug-induced liver injury: A clinical update. Curr. Opin. 
Gastroenterol., 26(3): 222-226.

2. Osna, N.A., Donohue, T.M. and Kharbanda, K.K. (2017) Alcoholic liver disease: Pathogenesis and current management. Alcohol Res., 38(2): 147-161.

3. Cichoz-Lach, H. and Michalak, A. (2014) Oxidative stress as a crucial factor in liver diseases. World J. Gastroenterol., 20(25): 8082-8091.

4. Ritesh, K.R., Suganya, A., Dileepkumar, H.V., Rajashekar, Y. and Shivanadappa, T. (2015) A single acute hepatotoxic dose of $\mathrm{CCl}_{4}$ causes oxidative stress in the rat brain. Toxicol. Rep., 2(2015): 891-895.

5. Hong, F., Si, C., Gao, P., Cederbaum, A.I., Xiong, H. and $\mathrm{Lu}, \mathrm{Y}$. (2016) The role of CYP2A5 in liver injury and fibrosis: Chemical-specific difference. Naunyn Schmiedebergs Arch. Pharmacol., 389(1): 33-43.

6. Rahal, A., Kumar, A., Singh, V., Yadav, B., Tiwari, R., Chakraborty, S. and Dhama, K. (2014) Oxidative stress, prooxidants, and antioxidants: the interplay. Biomed Res Int., 2014: 761624

7. Diao, Y., Zhao, X.F., Lin, J.S., Wang, Q.Z. and Xu, R.A. (2011) Protection of the liver against $\mathrm{CCl}_{4}$-induced injury by intramuscular electrotransfer of a Kallistatin-encoding plasmid. World J. Gastroenterol., 17(1): 111-117.

8. Al-Razzuqi, R., Al-Jawad, F.H., Al-Hussaini, J.A. and Al-Jeboori, A. (2012) Hepatoprotective effect of Glycyrrhiza glabra in carbon tetrachloride-induced model of acute liver injury. J. Phys. Pharm. Adv., 2(7): 259-263.

9. Liu, Q., Zhu, M., Geng, X., Wang, H. and Ng, T.B. (2017) Characterization of polysaccharides with antioxidant and hepatoprotective activities from the edible mushroom Oudemansiella radicata. Molecules, 22(2): 234-249.

10. Xiong, F. and Guan, Y.S. (2017) Cautiously using natural medicine to treat liver problems. World J. Gastroenterol., 23(19): 3388-3395.

11. Ahmad, M.F. (2018) Ganoderma lucidum: Persuasive biologically active constituents and their health endorsement. Biomed. Pharmacother., 107(2018): 507-519.

12. Friedman, M. (2016) Mushroom polysaccharides: Chemistry and antiobesity, antidiabetes, anticancer, and antibiotic properties in cells, rodents, and humans. Foods, 5(4): E80.

13. Zou, Y., Du, F., Hu, Q. and Wang, F. (2019) The structural characterization of a polysaccharide exhibiting antitumor effect from Pholiota adiposa mycelia. Sci. Rep., 9(1): 1724.

14. Zhao, C., Fan, J., Liu, Y., Guo, W., Cao, H., Xiao, J., Ying, W. and Liu, B. (2019) Hepatoprotective activity of Ganoderma lucidum triterpenoids in alcohol-induced liver injury in mice, an iTRAQ-based proteomic analysis. Food Chem., 271(2019): 148-156.

15. Quan, J., Yin, X. and Xu, H. (2011) Boschniakia rossica prevents the carbon tetrachloride-induced hepatotoxicity in rat. Exp. Toxicol. Pathol., 63(1-2): 53-59.

16. Ferenci, P. (2016) Silymarin in the treatment of liver diseases: What is the clinical evidence? Clin. Liver Dis., 7(1): 8-10.

17. Li, T.H., Hu, H.P., Deng, W.Q., Wu, S.H., Wang, D.M. and Tsering, T. (2014) Ganoderma leucocontextum, a new member of the G. lucidum complex from Southwestern China. Mycoscience, 56(1): 81-85.

18. Xiao, J., Liong, E.C., Ching, Y.P., Chang, R.C.C., So, K.F., Fung, M.L. and Tipoe, G.L. (2012) Lycium barbarum polysaccharides protect mice liver from carbon tetrachloride-induced oxidative stress and necroinflammation. J. Ethnopharmacol., 139(2): 462-470.

19. Nithya, M., Ambikapathy, V. and Panneerselvam, A. (2015) In vivo antioxidant and enzymatic activity of Ganoderma lucidum (Curt: Fr.) P. Karst. on mammary cells of DMBA induced Sprague Dawley rats. Int. J. Curr. Microbiol. Appl. Sci., 4(6): 69-77.

20. Xie, Y.Z., Yang, F., Tan, W., Li, X., Jiao, C., Huang, R. and Yang, B.B. (2016) The anti-cancer components of Ganoderma lucidum possesses cardiovascular protective effect by regulating circular RNA expression. Oncoscience, 3(7-8): 203-207.

21. Wadt, N.S.Y., Okamoto, M.K.H., Hi, E.M.B. and Bach, E.E. (2015) Chemical, toxicological, anti-inflammatory and antimicrobial evaluation of Ganoderma lucidum extracts. Emir. J. Food Agric., 27(7): 577-584.

22. Martinez-Montemayor, M.M., Ling, T., SuarezArroyo, I.J.S., Ortiz-Soto, G., Santiago-Negron, C.L., Lacourt-Ventura, M.Y., Valentin-Acevedo, A., Lang, W.H. and Rivas, F. (2019) Identification of biologically active Ganoderma lucidum compounds and synthesis of improved derivatives that confer anti-cancer activities in vitro. Front. Pharmacol., 10: 115.

23. Sun, X.Z., Liao, Y., Li, W. and Guo, L.M. (2017) Neuroprotective effects of Ganoderma lucidum polysaccharides against oxidative stress-induced neuronal apoptosis. Neural Regen. Res., 12(6): 953-958.

24. Lakshmi, B., Ajith, T.A., Jose, N. and Janardhanan, K.K. (2006). Antimutagenic activity of methanolic extract of Ganoderma lucidum and its effect on hepatic damage caused by benzopyrene. J. Ethnopharmacol., 107(2): 297-303.

25. Manibusan, M.K., Odin, M. and Eastmond, D.A. (2007) Postulated carbon tetrachloride mode of action: A review. $J$. Environ. Sci. Health C Environ. Carcinog. Ecotoxicol. Rev., 25(3): 185-209.

26. Recknagel, R.O., Glende, E.A. Jr., Dolak, J.A. and Waller, R.L. (1989) Mechanism of carbon tetrachloride toxicity. Pharmacol. Ther., 43(1): 139-154.

27. Ramaiah, S.K. (2007) A toxicologist guide to the diagnostic interpretation of hepatic biochemical parameters. Food Chem. Toxicol., 45(9): 1551-1557.

28. Yang, Y.S., Ahn, T.H., Lee, J.C., Moon, C.J., Kim, S.H., Jun, W., Park, S.C., Kim, H.C. and Kim, J.C. (2008). Protective effects of pycnogenol on carbon tetrachloride-induced hepatotoxicity in Sprague-Dawley rats. Food Chem. Toxicol., 46(1): 380-387.

29. Atiba, A.S., Abbiyesuku, F.M., Oparinde, D.P., NiranAtiba, T.A. and Akindele, R.A. (2016) Plasma malondialdehyde (MDA): An indication of liver damage in women with pre-eclampsia. Ethiop. J. Health Sci., 26(5): 479-486.

30. Kurutas, E.B. (2016) The importance of antioxidants which play a role in cellular response against oxidative/nitrosative stress: Current state. Nutr. J., 15(1): 71.

31. Mahmud, Z.A., Bachar, S.C. and Qais, N. (2012) Antioxidant and hepatoprotective activities of ethanolic extracts of leaves of Premna esculenta Roxb. against carbon tetrachloride-induced liver damage in rats. J. Young Pharm., 4(4): 228-234.

32. Singh, D., Arya, P.V., Aggarwal, V.P. and Gupta, R.S. (2014) Evaluation of antioxidant and hepatoprotective activities of Moringa oleifera Lam. leaves in carbon tetrachloride intoxicated rats. Antioxidant, 3(3): 569-591. 